\title{
Behaviour of Bagasse Ash and Bagasse Fibre in Concrete
}

\author{
Pandian Venkatesan ${ }^{1 *}$, Ramasamy Vasudevan ${ }^{1}$ \\ ${ }^{1}$ Research Scholar, SathyabamaInstitute of Science and Technology, Chennai,Tamil Nadu, \\ India \\ ${ }^{2}$ Dean \& Professor, Adhiparasakthi Engineering College, Melmaruvathu, Tamil Nadu, India
}

Email: vpandian2021@gmail.com

\begin{abstract}
Concrete is used for most of the buildings and bridgesconstruction in India can be called the backbone to the infrastructural development of the nation. However, the increase in the cost of cement not only increases the budget of a building but also poses a serious threat to the country's development.This study represents the flexural behaviour of bagasse ash concrete with bagasse fibre. Cement replaced with bagasse ash to reduce the environmental pollution and also with the bagasse ash,bagasse fibre is also incorporate on the concrete.Cement replaced with 10 and 20 percent ofbagasse ash with the addition of land 2 percent of bagasse fibre. Due to the massive amount of agricultural waste, the utilization of a number of them in concrete production reduces production residues and problems caused by the lack of recycling. Bagasse is that the pulp produced after sugarcane extraction. Due to the shortage of conversion industries, sugarcane factories produce about 1.2 million plenty of bagasse annually. In today's times, due to the progress ofvaried scientific fields, the concrete industry has also developed. The results show clearly the assembly of concrete containing pozzolan bagasse is additionally the results of an equivalent improvement in concrete.
\end{abstract}

Keywords: Behaviour, Bagasse Ash, Bagasse Fiber, Fibre, Concrete, Ordinary Portland cement

\section{Introduction}

Ordinary Portland cement is recognized as a major construction material throughout the world.Researchers all over the world today are focusing on ways of utilizing either industrial or agricultural waste, as a source of raw materials for industry. Concrete is the one of the most widely used construction material. The Portland cement production is a major contributor to $\mathrm{CO} 2$ emission. Many efforts and researches are being made in order to reduce the use of Portland cement in concrete making by replacing of cement with various pozzolonic materials like flyash, sugarcane bagasse ash( SCBA), ground granulated blast furnace slag (GGBS) and silicafume, etc., to improve quality and reduce the cost of construction materials $0,0.5 \%, 1 \%$ and $1.5 \%$ by the volume fraction of concrete were estimated. This paper analyzes the effect of SCBA in concrete by partial replacement of cement at the ratio of $0 \%, 5 \%, 10 \%, 15 \%$ and $25 \%$ by weight. The experimentalstudy examines the compressive strength, split tensile strength, flexural strength, 
young'smodulus and density of concrete. This objective of this work to study the flexural behaviour of bagasse ash concrete with bagasse fibre.

A few scholastic researchers from all over the world have conducted a study on sugarcane bagasse ash as a substitution material for cement. Most of the researchers utilized $(0 \%, 5 \%, 15 \%$, and $25 \%)$ of sugarcane bagasse ash as a substitution material for cement and study the effect of sugarcane bagasse ash on the mechanical, durable and flexure properties (Qing Xu, et al., . (2019) Kawade, et.al. (2013), they found that using sugarcane bagasse ash as a cement substitution material enhanced the mechanical, durable and flexure properties of concrete. And depending on the ratio utilized the results will improve further. Researchers observed that the replacement of sugarcane bagasse ash as a reused material limits our reliance on regular assets in the development business. The utilization of reused materials in the concrete can provide more development in the construction industry, and sugarcane bagasse ash provides good strength on the concrete (Sandela (2010)). Subsequently, the waste can be used as a substitution in the development industry in this way dispensing with the unloading issue to a degree wherein it benefits the earth (Amit, 2018).

India is the second-biggest maker of sugarcane and a huge amount of bagasse debris (67,000 tons/day) is straightforwardly arranged to the closest land which causes serious natural issues (A. Ahmed 2019). Quick usage of bagasse based new cogeneration plants is relied upon to generously build bagasse debris age. The use of bagasse debris as a beneficial establishing material through methodical preparing and portrayal offers a productive and climate neighbourly option in contrast to its removal.

Pozzolanic materials, for example, sugarcane bagasse debris and rice husk debris are rural results and can't be straightforwardly utilized as a mineral admixture in cement because of the presence of unburnt particles (A. Ahmed 2019). Rather than direct expansion in concrete as substitution materials, the appropriate portrayal of new pozzolanic material, thorough investigation about the impact of different preparing techniques on its pozzolanic execution and execution assessment of new materials in cement are basic to accomplish a successful pozzolanic material with the least degree of energy inputs.

Aside from regular supplementary cementitious materials, a few different materials have been related to a nearby point of view all around the world. One conspicuous option supplementary cementitious material is sugarcane bagasse ash, which is acquired after controlled consuming of the bagasse (that is leftover in the wake of extricating the sugarcane juice) in cogeneration plants related with the sugarcane manufacturers. Sugarcane bagasse ash is having a good volume of silica that provides great pozzolanic properties (B.S. Shameem 2020).

Venkatesh, K. R et al. (2018) considered cement replaced with the bagasse ash at $650^{\circ} \mathrm{C}$ burnt for $1 \mathrm{~h}$ and ground to $5.4 \mu \mathrm{m}$ sieved particles. J. Paya et al. (2018) ground bagasse debris to under $90 \mu \mathrm{m}$ sieved size and bagasse ash provided the extraordinary effect on the mechanical and flexure properties. In prior examination considers, sugarcane bagasse 
debris was burnt and sieved to various inexact temperatures to eliminate unburnt particles just as a ground to solidify size and utilized as a mineral admixture in the cement for the presentation assessment, without adequate comprehension of the material by the appropriate portrayal and legitimate preparing. It is fundamental to assess the presence of bagasse ash to encourage its powerful use in concrete as a replacement for cement. In this investigation, Sugarcane bagasse ash concretes were utilized for the study to evaluate the concrete with the replacement of cement. The ordinary Portland cement was replaced with the bagasse ash with the five different variables $(5 \%, 10 \%, 15 \%, 20 \%$ and 25\%). From the investigation on the sugarcane bagasse ash concrete, the strength and durability were potential on the concrete.

Some examination $[14,15,16]$ has been conducted a study on sugarcane bagasse ash to explore the pozzolanic responses and propriety as bindery supplanting the cement to some degree. This exploration was led on sugarcane bagasse ash. This exploration investigation the impact of sugarcane bagasse ash in concrete as a fractional concrete replacement by $(0,3,5$, 7 and 10) \% by weight. The significant parts were ordinary Portland cement, sugarcane bagasse ash, sand as a fine aggregate, gravel as a coarse aggregate, water, and combination 90 of superplasticizer. From the examination, sugarcane bagasse ash provides an excellent pozzolanic response on the concrete.

\section{Materials and Methods}

Figure 1 and 2 shows the bagasse ash and bagasse fibre53 grade Ordinary Portland cement was used in this work. Sugarcane bagasse ash was used as a replacement for cement in different percentages. Fine aggregates conforming to zone II of IS code. Coarse aggregate was a crushed stone with angular of $10 \mathrm{~mm}$ to $20 \mathrm{~mm}$. Potable quantity water was used. In addition to all the bagasse fibre was also added with an aspect ratio of 50/70.

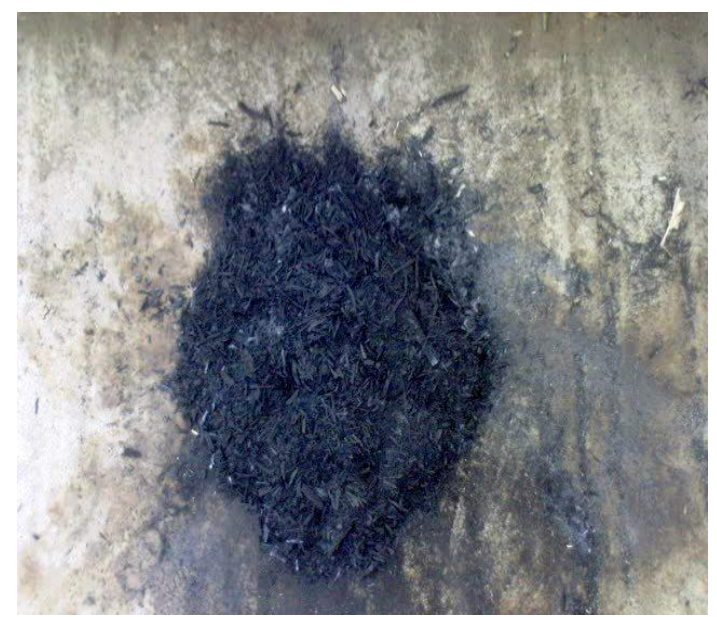

Fig 1. Bagasse Ash

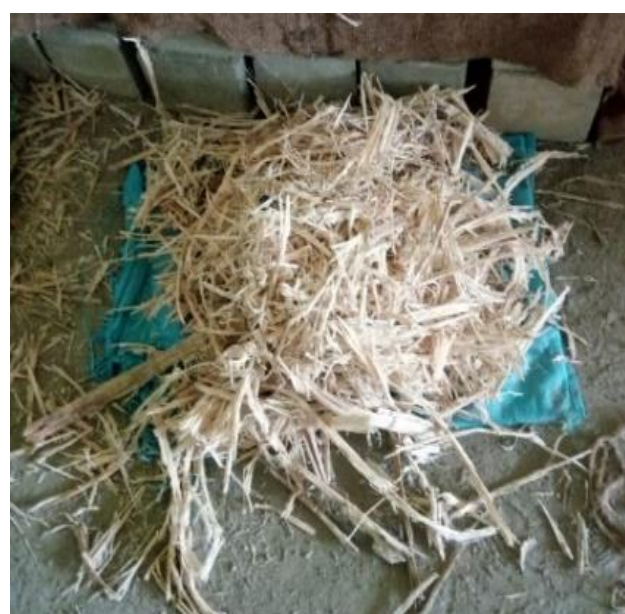

Fig 2. Bagasse Fibre

This study examines the behaviour of concrete beam with and without bagasse ash and bagasse fibre. M30 grade concrete beam is cast and tested. The size of the tested beam is 150x250x2000mm. The study contains two different materials having bagasse ash and bagasse fibre. The bagasse ash is used as a replacement for cement with a ratio of $10 \%$ and $20 \%$. The bagasse fibre is added with the bagasse ash in concrete to improve the flexure 
strength with the percentage of $1 \%$ and $2 \%$.Table 1 .Shows the details of the specimen used in this study.

Table 1: Specimen Details

\begin{tabular}{|c|c|c|c|}
\hline S.No & Beam Designation & Bagasse ash in \% & Bagasse fibre in \% \\
\hline 1 & CC & - & - \\
\hline 2 & BA10BF1 & 10 & 1 \\
\hline 3 & BA10BF2 & 10 & 2 \\
\hline 4 & BA20BF1 & 20 & 1 \\
\hline 5 & BA20BF2 & 20 & 2 \\
\hline
\end{tabular}

The bagasse ash properties used as 2.52 of density with a surface area of $5140 \mathrm{~cm}^{2} / \mathrm{gm}$. The bagasse ash was sieved with the $45 \mu \mathrm{m}$ and its colour was reddish grey. Silica plays a major role in the bagasse ash chemical properties with a percentage of $66.89 \%$. The alumina\& ferric oxide on the bagasse ash percentage was $29.18 \%$.

\section{Experimental work}

The loading frame was used for this study for all the beams. All the beams were tested after 28days ages of curing under two-point loading over the span. The deflections were measured at the loading points and maximum deflection was measured at the mid of the span. The deflection was measured using a dial gauge of $0.01 \mathrm{~mm}$ accuracy. Figure 2 shows the test set-up of the beams.

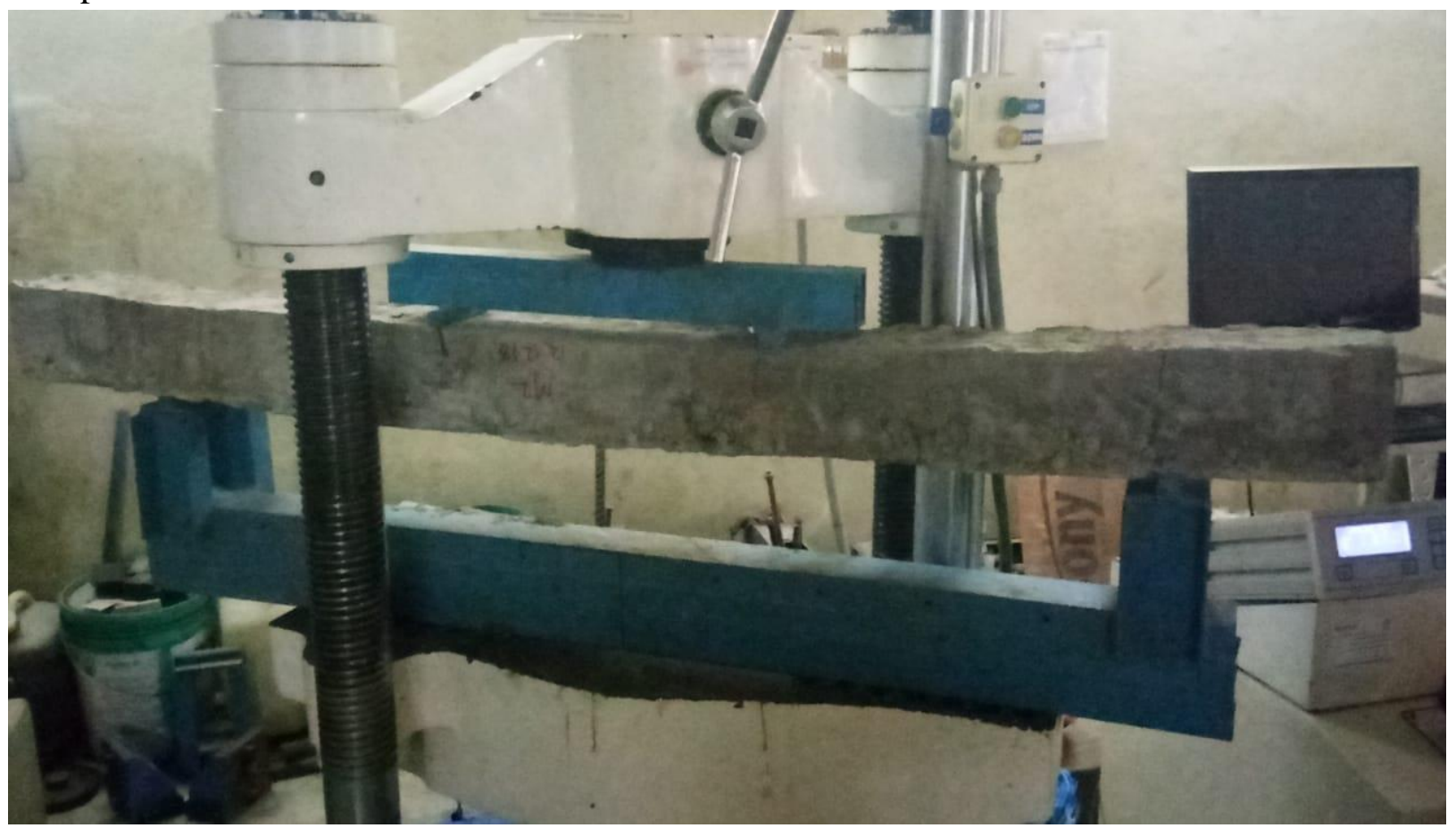

Fig 2. Test Set-up of the beams

During the beam test, the behaviour of the beam was noted, the measurements on the beam taken until failure. 


\section{Results and Discussion}

The behaviour of the reinforced concrete beam and bagasse ash concrete beams with bagasse fibre was investigated in the yield and ultimate stage of the load-deflection response. Besides, a study was conducted to elaborate on the properties of concrete beams at different stages with the variables of the beams. Table 2 shows the test results of the beams at the yield and ultimate stages.

Table 2: Test Results on the Beam Specimens

\begin{tabular}{|c|c|c|c|c|c|}
\hline S.No & $\begin{array}{c}\text { Beam } \\
\text { Designation }\end{array}$ & $\begin{array}{c}\text { Yield } \\
\text { Load } \\
\text { in kN }\end{array}$ & $\begin{array}{c}\text { Yield } \\
\text { Deflection } \\
\text { in } \mathbf{~ m m}\end{array}$ & $\begin{array}{c}\text { Ultimate } \\
\text { Load in } \\
\mathbf{k N}\end{array}$ & $\begin{array}{c}\text { Ultimate } \\
\text { Deflection } \\
\text { in } \mathbf{~ m m}\end{array}$ \\
\hline 1 & CC & 24.5 & 5.55 & 31.1 & 6.81 \\
\hline 2 & B10F1.0 & 33.5 & 4.65 & 39.5 & 7.75 \\
\hline 3 & B10F2.0 & 27.5 & 5.05 & 36.5 & 7.55 \\
\hline 4 & B20F1.0 & 27.5 & 5.00 & 32.6 & 7.05 \\
\hline 5 & B20F2.0 & 25.5 & 5.65 & 28.4 & 6.45 \\
\hline
\end{tabular}

Table 3: Ductility of Tested Beams

\begin{tabular}{|l|l|l|l|l|l|}
\hline S.No & $\begin{array}{l}\text { Beam } \\
\text { Designation }\end{array}$ & $\begin{array}{l}\text { Deflection } \\
\text { Ductility }\end{array}$ & $\begin{array}{l}\text { Deflection } \\
\text { Ductility } \\
\text { Ratio }\end{array}$ & $\begin{array}{l}\text { Energy } \\
\text { Ductility } \\
\text { KN/mm }\end{array}$ & $\begin{array}{l}\text { Energy } \\
\text { Ductility } \\
\text { Ratio }\end{array}$ \\
\hline 1 & CC & 1.23 & 1.00 & 107.70 & 1.00 \\
\hline 2 & B10F1.0 & 1.67 & 1.36 & 186.56 & 1.73 \\
\hline 3 & B10F2.0 & 1.50 & 1.22 & 157.35 & 1.46 \\
\hline 4 & B20F1.0 & 1.41 & 1.15 & 127.91 & 1.19 \\
\hline 5 & B20F2.0 & 1.14 & 0.93 & 94.96 & 0.88 \\
\hline
\end{tabular}

Table 3 shows the ductility of tested beams. The deflection ductility ratio was increased on bagasse fibrereinforced concrete beams. The deflection ductility ratiofor the $10 \%$ bagasse ash by volume of cement with $1 \%$ of bagasse fibreincreases the deflection ductility ratio by $36.05 \%$ when compared with the normal reinforced concrete beam. The deflection ductility ratio for the $10 \%$ bagasse ash by volume of cement with $2 \%$ of bagasse fibreincreases the deflectionductility ratio by $22.5 \%$ when compared with the normal reinforced concrete beam. The deflection ductilityratiofor the $20 \%$ bagasse ash by volume of cement with $1 \%$ of bagasse fibreincreases the deflectionductility ratio by $15.06 \%$ when compared with the normal reinforced concrete beam. The deflection ductilityratio for the $20 \%$ bagasse ash by volume of cement with $2 \%$ of bagasse fibredecreases the deflectionductility ratio by $17.05 \%$ when compared with the normal reinforced concrete beam. 
Bagasse ash reinforced concrete beams with bagasse ash experienced an increase in load at yield and ultimate stages. It shows the consequence of the bagasse ash on the concrete plays a vital role to increase the load on the various stages. The deflection on the beams also reduced due to the presence of bagasse fibre.

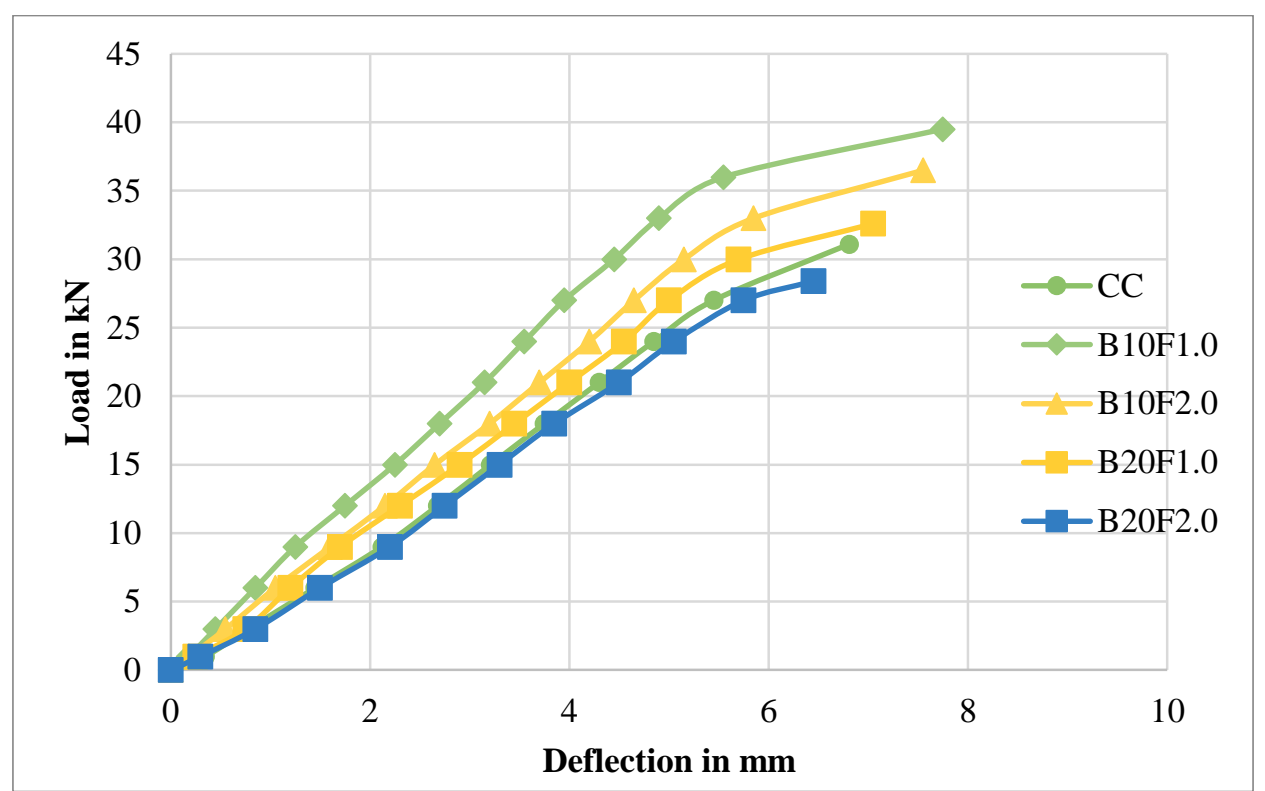

Fig 3. Load Vs Deflection of concrete Beam with and with Bagasse ash \& Bagasse Fibre

The inclusion of bagasse ash concrete at $10 \%$ by volume of cement with $1 \%$ of bagasse fibre increases the yield load by $28.94 \%$ when compared with the normal reinforced concrete beams at yield load.The inclusion of bagasse ash concrete at $10 \%$ by volume of cement with $2 \%$ of bagasse fibre increases the yield load by $9.65 \%$ when compared with the normal reinforced concrete beams at yield load. The inclusion of bagasse ash concrete at $20 \%$ by volume of cement with $1 \%$ of bagasse fibre increases the yield load by $9.65 \%$ when compared with the normal reinforced concrete beams at yield load. The inclusion of bagasse ash concrete at $20 \%$ by volume of cement with $2 \%$ of bagasse fibredecreases in the yield load by $8.62 \%$, when compared with the normal reinforced concrete beams at yield load.

The inclusion of bagasse ash concrete at $10 \%$ by volume of cement with $1 \%$ of bagasse fibre increases the ultimate load by $27.01 \%$ when compared with the normal reinforced concrete beams at ultimate load.The inclusion of bagasse ash concrete at $10 \%$ by volume of cement with $2 \%$ of bagasse fibre increases the ultimate load by $17.36 \%$ when compared with the normal reinforced concrete beams at ultimate load. The inclusion of bagasse ash concrete at $20 \%$ by volume of cement with $1 \%$ of bagasse fibre increases the ultimate load by $4.83 \%$ when compared with the normal reinforced concrete beams at ultimate load.The inclusion of bagasse ash concrete at $20 \%$ by volume of cement with $2 \%$ of bagasse fibredecreases in the ultimate load by $8.62 \%$, when compared with the normal reinforced concrete beams at ultimate load. 
The deflection was decreased due to the presence of bagasse fibre on the concrete beams. The deflection at yield load for the $10 \%$ bagasse ash by volume of cement with $1 \%$ of bagasse fibre decreases the deflection by $13.22 \%$ when compared with the normal reinforced concrete beam deflection at the yield load stage.The deflection at yield load for the $10 \%$ bagasse ash by volume of cement with $2 \%$ of bagasse fibre decreases the deflection by $25.84 \%$ when compared with the normal reinforced concrete beam deflection at yield load stage. The deflection at yield load for the $20 \%$ bagasse ash by volume of cement with $1 \%$ of bagasse fibre decreases the deflection by $8.08 \%$ when compared with the normal reinforced concrete beam deflection at the yield load stage. The deflection at yield load for the $20 \%$ bagasse ash by volume of cement with $2 \%$ of bagasse fibre decreases the deflection by $1.3 \%$ when compared with the normal reinforced concrete beam deflection at the yield load stage.

The deflection was decreased due to the presence of bagasse fibre on the concrete beams. The deflection at ultimate load for the 10\% bagasse ash by volume of cement with $1 \%$ of bagasse fibre decreases the deflection by $13.08 \%$ when compared with the normal reinforced concrete beam deflection at the ultimate loadstage. The deflection at ultimate load for the $10 \%$ bagasse ash by volume of cement with $2 \%$ of bagasse fibre decreases the deflection by $10.86 \%$ when compared with the normal reinforced concrete beam deflection at the ultimate loadstage. The deflection at ultimate load for the $20 \%$ bagasse ash by volume of cement with $1 \%$ of bagasse fibre decreases the deflection by $8.52 \%$ when compared with the normal reinforced concrete beam deflection at the ultimate load stage. The deflection at ultimate load for the $20 \%$ bagasse ash by volume of cement with $2 \%$ of bagasse fibre decreases the deflection by $5.1 \%$ when compared with the normal reinforced concrete beam deflection at the ultimate loadstage.

The results indicate the addition of bagasse ash improves the strength of the concrete beams. The addition of bagasse fibre to a control concrete could exhibit increase strength and reduces the deflection. The load-deflection curves of the test beams show similar behaviour on reinforced concrete beams and bagasse ash reinforced concrete beams with bagasse fibre. The test beams behaviour of all the specimens is divided by microcrack stage, yielding on the steel reinforcement, nonlinearity on the beams due to increased loading. The load-deflection graph shows the flexural behaviour of the bagasse ash concrete with bagasse fibre stages was good compared with the reinforced concrete beams. All the beam specimens were failed due to flexure. All the beams achieved the three stages of the beams fails after the tensile reinforcement yielding.

The energy absorption of the bagasse ash reinforced concrete beam with bagasse fibre show good results when compared with the reinforced concrete beams. The energy ductility ratio for the $10 \%$ bagasse ashby volume of cement with $1 \%$ of bagasse fibreincreases the energy ductility ratio by $73 \%$ when compared with the normal reinforced concrete beam. The energy ductility ratio for the $10 \%$ bagasse ash by volume of cement with $2 \%$ of bagasse fibreincreases the energy ductility ratio by $46 \%$ when compared with the normal reinforced concrete beam. The energy ductility ratio of the $20 \%$ bagasse ash by volume of cement with 
$1 \%$ of bagasse fibreincreases the energy ductility ratio by $19 \%$ when compared with the normal reinforced concrete beam. The energy ductility ratio for the $10 \%$ bagasse ash by volume of cement with $2 \%$ of bagasse fibredecreases the energy ductility ratio by $12 \%$ when compared with the normal reinforced concrete beam.

\section{Conclusion}

The yield load, yield deflection, ultimate load, ultimate deflection, deflection ductility, deflection ductility ratio, energy ductility and energy ductility ratio tested beams shows immense response on the inclusion of $10 \%$ of bagasse ash reinforced concrete beams with $1 \%$ of bagasse fibre.The results further concluded that the addition of bagasse ash and bagasse fibre on the concrete beams improves the behaviour of concrete. The bagasse ash and bagasse fibrewasa good solution for the replacement of cement.

\section{References}

[1] Qing Xu, Q., Ji, T., Gao, S. J., Yang, Z., \& Wu, N. (2019). Characteristics and Applications of Sugar Cane Bagasse Ash Waste in Cementitious Materials, Materials, 12(39).

[2] Abbas, A. N., Al-Nealy, H., Al-Saadi, A., \& Imran, M. (2020). The Effect of Using SugarCane Bagasse Ash as a Cement Replacement on the Mechanical Characteristics of Concrete. In Materials Science Forum (Vol. 1002, pp. 565-577). Trans Tech Publications Ltd.

[3] Amit, \& Sahil, G. (2018). To Study the Properties of Concrete using Bagasse Ashon M-25 Grade of Concrete. International Journal of Current Engineering andTechnology, 8(4), 968972

[4] B.S. Shameem, J. Karthikeyan, P. Jayabalan Effect of agro-waste on strength and durability properties of concrete Cons. Build. Mater., 258 (2020), 10.1016/j.conbuildmat.2020.120322

[5] Venkatesh, K. R., R. Rani, R., Thamilselvi, M., \& Rajahariharasudhan, R. (2018).Experimental Study on Partial Replacement of Cement With SugaecaneBagasse Ash in Concrete. International Journal of Advance Engineering andResearch Development, 05(04), 778-785

[6] A. Ahmed, O.A.U. Uche, M.T. Abdulwahab, N.U. Amali, Mechanical properties ofsugarcane straw waste ash used as binder in concrete production, FUW TrendsSci. Technol. J. 4 (1) (2019) 247-249.

[7] U.R. Kawade, V.R. Rathi, V.D. Girge(2013), Effect of use of bagasse ash on strength of concrete,International Journal of Innovative Research in Science, Engineering and Technology, 2, 2997-3000.

[8] Frias M, Villar E, SavastanoH(2011), Brazilian sugar cane bagasse ashes from the cogeneration industry as active pozzolans for cement manufacture, Cement Concrete Composite, 33, 490-496.

[9] J. Paya, J. Monzo, M.V. Borrachero, M.M. Tashima, L. Soriano, Bagasse ash,Waste Suppl. Cement. Mater. Concr. (2018) 559-598

[10] J.A. Patel, D.B. Raijiwala(2015), Use of Sugar Cane Bagasse Ash as Partial Replacement of Cement in Concrete - An Experimental Study, Global journal of Research in Engineering, 15(5), 1-7. 
[11] M. Jahanzaib Khalil, M. Aslam and S. Ahmad, (2020), Utilization of sugarcane bagasse ash as cement replacement for the production of sustainable concrete - A review, Construction and Building Materials, https://doi.org/10.1016/j.conbuildmat.2020.121371

[12] Nuntachai C, Chai J, KraiwoodK(2009), Utilization of bagasse ash as a pozzolanic material in concrete, Construction Building Materials,23, 3352-3358.

[13] Cordeiro GC, Toledo Filho RD, Tavarse LM, Fairbairn EM, Hempel S(2011), Influence of particle size and specific surface area on the pozzolanic activity of residual ricehuskash,cement concrete composites, 33, 529-34.

[14] Ganesan K, Rajagopal M, ThangavelK(2007), Evaluation of bagasse ash as supplementary cementitious material, cement concrete composites, 29, 515-24. 